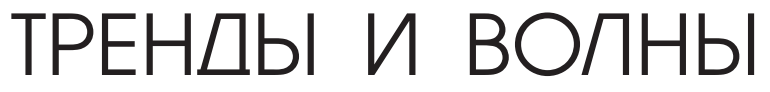 МОДЕРНИЗАЦИИ
}

И.М. Соколов

\section{ЭФФЕКТИВНОСТЬ ГОСУДАРСТВЕННЫХ РЕШЕНИЙ В УСЛОВИЯХ МОДЕРНИЗАЦИИ: ОПЫТ СТРАН МИРА}

Аннотация: В статье рассматривается зарубежный опыт реализации модернизационных изменений в условиях тоталитарной, авторитарной и демократической модели принятия решений. Дается оценка эффективности управленческих решений руководства стран Германии, Чили и США на различных этапах политического развития.

Ключевые слова: Политология, модернизаџия, государственное решение, модели принятия решений, государство, Чили, США, Германия, Рузвельт, эффективность

егодня в России началась уже не первая за несколько последних десятилетий модернизация, задачи которой, как всегда, грандиозны. Обозначены цели модернизации, выбраны ее направления, начались приниматься конкретные государственные решения ${ }^{1}$. Все эти события лишь в очередной раз подстегивают научную общественность к новому ветку изучения данного вопроса.

Саму модернизацию как процесс, на наш взгляд, можно представить как переход системы (прим. автора: в нашем случае этой системой является государство, общество) в новое состояние. Теоретически это новое состояние должно быть качественно лучше. Если рассматривать модернизацию в этом ключе, то сам процесс «перехода» можно разбить на решения, которые этот переход обеспечивают.

В этом случае эффективность модернизации как стратегического решения, будет зависеть от эффективности принимаемых тактических решений. Эффективность принимае-

${ }^{1}$ Медведев Д.А. Россия, вперёд! http://kremlin.ru/ news/5413 мых решений тесно связана с понятием цели. То есть эффективными решениями можно назвать лишь те решения, которые достигают поставленных целей, в противном случае эти решения неэффективны. В модернизации как в стратегическом проекте все тоже самое. То есть в контексте эффективности принимаемых решений мы можем проследить всю модернизацию и сделать вывод о том, насколько этот проект был эффективным.

Особую роль в оценке эффективности принимаемых решений следует уделить так называемой типологии государственных решений. Согласно этой типологии все решения можно разделить на демократические, авторитарные и тоталитарные модели принятия решений.

Демаркационные линии между этими моделями можно провести в зависимости от степени влияния, которую оказывают друг на друга общество и государство. То есть, в тоталитарных моделях принятия решения государство ${ }^{2}$ полностью (тотально) влияет на

\footnotetext{
2 Прим. автора: в данном случае под государством мы понимаем систему управления обществом.
} ENE (ООО «НБ-Медиа») www.nbpublish.com 


\section{Тренды и управление - № 2 (2)•2013}

все сферы жизнедеятельности общества, фактически общество полностью контролируется государством, затрагивая все процессы жизнедеятельности. В тоталитарных моделях влияние государства на общество высоко, общество фактически не имеет влияния.

В авторитарных моделях принятия решения государство влияет только на конкретные значимые для государства как системы сферы общества (например, экономическая, политическая). В остальном общество получает относительную свободу действий, но эта свобода ограничивается репрессивными органами, когда общество вторгается в интересы государства. В авторитарных моделях влияние государства на общество ограничено сферами интересов государства, общество при необходимости способно оказать влияние на некоторые не значимые для государства сферы.

В демократических моделях общество контролирует государство, общество становится единственным легитимным источником власти. Решения принимаются через коллективные методы принятия решений (например, голосование), с равной силой воздействия на этот процесс всех участников процесса. В этой модели государство находится на службе у общества, влияние общества тотально.

Несомненно, данная типология не претендует на абсолютную научную полноту и, возможно, требует уточнения, однако, она позволяет, с нашей точки зрения, удачно оценить эффективность решений руководства ряда зарубежных стран в условиях модернизации.

Пул зарубежных стран, в которых в разное время осуществлялась модернизация, определен мировой историей. В соответствии с типологией, которая была обозначена выше, мы отобрали ряд примеров из мировой истории, где наиболее ярко, с нашей точки зрения, проявились демаркационные черты моделей принятия решений. Кроме того, мы попытались найти в истории зарубежных стран такие периоды развития, в которых модернизация и принятые в рамках нее государственные решения были по-настоящему эффективны.

Среди ярких примеров зарубежной истории мы выделили Германию 1933-1936 годов как пример моделей тоталитарных решений, США в период «Нового курса» президента Ф. Д. Рузвельта (1933-1941) - это пример демократической модели принятия решений. Наконец, «чилийское чудо» генераладиктатора А. Пиночета будет ярким примером авторитарной модели. По мнению ряда исследователей, решения правительств указанных стран в условиях проводимых ими реформ были эффективными и достигали своих целей в определенной исторической перспективе. Несомненно, опыт этих стран, как успешно реализовавших реформы на историческом витке своего развития, заслуживает особого внимания со стороны российских реформаторов.

Мы не случайно выбрали для анализа Германию 1933-1936 годов в качестве примера эффективности тоталитарной модели управления. В этот период немцам удалось вывести свое государство, свою экономику, качество жизни простых граждан на новый уровень. Несомненно, преступления укрепившегося в этот период немецкого фашизма заслуживают осуждения, и данный текст не стоит рассматривать как попытку что-то доказать, кого-то реабилитировать. Наша задача состоит в том, чтобы максимально объективно показать эффективность той или иной модели принятия решений в условиях модернизации.

Новое правительство Германии в 1933 году получило истощенную «Великой депрессией» и репарациями экономику с большим количеством безработных (около 6 миллионов человек, по некоторым данным - около $30 \%$ от всего населения). ${ }^{3}$

\footnotetext{
${ }^{3}$ Миронин С.С. Антидепрессивная политика Обамы, Сталина, Гитлера и Рузвельта http://www.zlev.ru/index.php?p=article\&n omer $=12$ \&article $=562$
} 
Основной целью правительства Германии до 1936 года, как нам кажется, было восстановление экономики и уменьшение уровня безработицы. Проблема безработицы в этот период была решена за счет общественных работ, среди которых были такие масштабные программы как «Имперский автобан», «строительство Реинхардта» Часть безработных удалось убрать с рынка труда за счет призыва в армию ${ }^{4}$. Правительство Германии запретило не только профсоюзы, но и забастовки, над рабочими установился тотальный контроль. ${ }^{5}$ Так или иначе, эти, порой мало популярные меры, способствовали значительному сокращению уровня безработицы, а уже в 1936 году в ряде отраслей промышленности была достигнута полная занятость ${ }^{6}$. Фактически цель правительства Германии по сокращению безработицы была достигнута, решения и реализация этих решений порой не отличались популярностью, но они были эффективными.

Задачи по восстановлению немецкой экономии отчасти были возложены на крупных промышленников и предпринимателей разных уровней. «Когда Гитлер стал канцлером, он первым делом собрал руководителей ведущих промышленных предприятий Германии и сообщил им, что раз они действуют в рамках корпоративной экономики, то будут подчиняться требованиям Рейха. Однако он заверил промышленников, что не собирается покушаться на их частную собственность и готов с ними сотрудничать с обоюдной выгодой». ${ }^{7}$ В экономике правительство

${ }^{4}$ Миронин С.С. Антидепрессивная политика Обамы, Сталина, Гитлера и Рузвельта http://www.zlev.ru/index. php? $p=$ article \&nomer $=12$ \&article $=562$

${ }^{5}$ Миронин С.С. Антидепрессивная политика Обамы, Сталина, Гитлера и Рузвельта http://www.zlev.ru/index. php?p=article \&nomer $=12 \&$ article $=562$

${ }^{6}$ Миронин С.С. Антидепрессивная политика Обамы, Сталина, Гитлера и Рузвельта http://www.zlev.ru/index. php?p=article \&nomer $=12 \&$ article $=562$

${ }^{7}$ Миронин С.С. Антидепрессивная политика Обамы,
Германии провело централизацию и перевело ее на жесткое планирование. «В стране практически провели своеобразную национализацию, огосударствление хозяйства, придав правящему классу корпоративноэлитарный характер ${ }^{8}$. Фактически, в этот период в Германии создалась командноадминистративная экономика (официально она называлась: «планкоммандвиртшафт» «планово-командное хозяйство»). ${ }^{9}$ Реформы правительства того периодазатронули всесферы от сельского хозяйства до банков, в результате, в период с 1932 по 1937 год промышленное производство возросло на $102 \%,{ }^{10}$ сократилась безработица, укрепилась правящая элита. Цель правительства была достигнута, реформы оказались эффективными.

Таким образом, правительству Германии удалось решить поставленные задачи, действуя командно-административными методами при абсолютной поддержке правящей партии. Страна вышла из кризиса путем модернизации, проведенной тоталитарными методами. Возможно, если бы Германия не разожгла огонь Второй Мировой Войны, реформы 19331936 гг. при немецкой организации и порядке были более эффективны и принесли большую пользу стране и ее народу. Курс правительства Германии, взятый в 1936 году по переводу экономики страны на военные рельсы, как показала история, оказался настоящей трагедией не только для немецкого народа, но и всего мирового сообщества. Объективности ради отметим, что немецкую тоталитарную

Сталина, Гитлера и Рузвельта http://www.zlev.ru/index. php? $=$ article \&nomer $=12 \&$ article $=562$

${ }^{8}$ Миронин С.С. Антидепрессивная политика Обамы, Сталина, Гитлера и Рузвельта http://www.zlev.ru/index. php?p=article\&nomer $=12$ \&article $=562$

${ }^{9}$ Миронин С.С. Антидепрессивная политика Обамы, Сталина, Гитлера и Рузвельта http://www.zlev.ru/index. php?p=article\&nomer $=12$ \&article $=562$

${ }^{10}$ Экономика Третьего рейха до и во время войны http:// ru.wikipedia.org/wiki/Третий рейx 


\section{Тренды и управление - № 2 (2)•2013}

модель смогла уничтожить другая, более мощная, тоталитарная модель - советская. Только Советский Союз смог остановить, а затем и уничтожить немецкую машину, причем руководство СССР использовало ту же тоталитарную модель принятия решений.

Сегодня во многих странах мира самой популярной является демократическая модель принятия решений. Одновременно сегодня существует большое количество вариантов демократии, например, американская и российская, французская и немецкая. Каждая страна вносит в демократическую модель свои уникальные национальные черты и особенности, поэтому сегодня в мире нет какой-то унифицированной демократической модели.

Реформы и модернизационные изменения в рамках демократической модели - процесс сложный, порой тянущийся десятилетиями. Не всегда реформы в демократических странах достигают поставленных целей, на каком-то этапе есть риск, что программы реформ могут утонуть в демократическом плюрализме. В этой связи опыт Франклина Делано Рузвельта и его «Новый курс» стоят особняком в истории демократии. Политика Рузвельта в годы его правления была непросто эффективной, 32-му президенту США удалось провести в стране серьезные изменения. Вывести страну из кризиса, провести ее через сложные внешнеполитические события, при этом Рузвельту удалось четыре раза избираться на пост Президента США (для американской демократии это уникальный случай). По нашему мнению, именно программа «Нового курса» стала краеугольным камнем успешных и эффективных решений Рузвельта, позволившая добиться ее инициатору положительных результатов для своей страны и народа.

Объективности ради также заметим, что, несмотря на демократию и многочисленные свободы американских граждан, Рузвельт действовал крайне решительно в банковской сфере (прим. автора: тоталитарными методами), в частности, в своих решениях по временному закрытию банков, политики по запрету частного владения золотом и ограничению распоряжения частными банковскими сбережениями. ${ }^{11}$

В социальной сфере Рузвельт активно использовал политику общественных работ, провел реформы, улучшил трудовое законодательство. Фактически в период правления Рузвельту удалось перезагрузить капитализм и представить его обществу «с человеческим лицом».

Результатами решений «Нового курса» стало оживление американской экономики и выход из «Великой депрессии». Однако, в настоящего лидера мировой экономики Соединенные штаты Америки смогли превратиться только во время Второй Мировой Войны. Справедливо заметим, что это произошло также при участии Рузвельта. По сути, курс Рузвельта, «являвшийся прямым массированным вторжением государства в сферу социально-экономических отношений и включавший значительные элементы регулирования, способствовал смягчению проявлений кризиса» ${ }^{12}$.

Таким образом, Рузвельт порой недемократическими методами добился желаемого эффекта, провел свои реформы и получил устраивавший некоторое время американское общество результат. В дальнейшем во избежание новых депрессий программы «Нового курса» были свернуты и заменены на систему сдержек и противовесов. Но политика Рузвельта как пример эффективной модели принятия решений в условиях демократии, по нашему глубокому убеждению, навсегда войдет в золотой фонд эффективного управления в условиях модернизации.

\footnotetext{
${ }^{11}$ Миронин С.С. Антидепрессивная политика Обамы, Сталина, Гитлера и Рузвельта http://www.zlev.ru/index. php? $p=$ article $\&$ nomer $=12 \&$ article $=562$

12 «Новый курс» Рузвельта http://ru.wikipedia.org/wiki/ Новый курс
} 
Хорошим примером модернизации в рамках авторитарной модели является опыт чилийских реформ. Модернизация в Чили получила название «чилийское чудо», хотя есть разные точки зрения на ее чудесные свойства. Так, например, американский экономист и нобелевский лауреат Милтон Фридман, руководитель экономической школы, которая предложила эту теорию «чуда», писал об этом так: «Истинное чудо, произошедшее в Чили, - это не отличные экономические результаты. Истинное чудо в том, что военная хунта сочла возможным пойти против собственных принципов и поддержать режим свободного рынка, построенный людьми, принципиально верящими в свободный рынок». ${ }^{13}$ Некоторые правые экономисты ставят опыт Чили в пример России. Пожалуй, самый известный из них экс-советник В.В. Путина Андрей Илларионов, считающий, что «чилийские реформы образец для остальных стран». ${ }^{14}$

Опыт чилийской либерализации в конце 80-х - начале 90-х годов XX века для либеральных экономистов новой России был чемто вроде «священной коровы». Однако не все разделяют взгляды либералов на «чилийское чудо». Так, например, сегодня появилась плеяда специалистов, разоблачающих «фокус чикагских мальчиков Фридмана». Среди них хочется отметить Стива Кангаса, ${ }^{15}$ Сергея Минаева ${ }^{16}$ и других специалистов. Работ по разоблачению «чилийского чуда» сейчас действительно очень много и все они приводят доскональную фактологию, которая разоблачает режим Пиночета.

\footnotetext{
${ }^{13}$ Буйвинд Э. Прощай, "чилийское чудо" http://rus.delfi. Iv/archive/article.php?id $=16512630$

${ }^{14}$ В России снова вспомнили про чилийское финансовое чудо http://top.rbc.ru/economics/03/07/2008/194783. shtml

${ }^{15}$ Кангас С. Чикагские мальчики и чилийское экономическое чудо http://www.scepsis.ru/library/id 557.html

${ }^{16}$ Минаев С. Чилийское экономическое чудище http:// www.kommersant.ru/doc.aspx?DocsID $=731005$
}

Таким образом, сегодня есть два крайних взгляда на чилийскую модернизацию времен Пиночета. Одни говорят, что это трагедия и обман, другие убеждены, что реформы Пиночета - это чудо. Опыт чилийской модернизации важен не просто как яркий пример принятия авторитарных решений в условиях модернизации, для россиян опыт «чилийского чуда» интересен еще тем, что его сценарий в какой-то мере был реализован в нашей стране.

Напомним, что Чили, в первую очередь, - страна, богатая ценным природным ресурсом - медью, которая ценится во всем мире. Аугусто Пиночет пришел на волне военного переворота к власти с программой преобразований. Прежде всего, это были преобразования чилийской экономики.

Правительство Пиночета в самом начале реформ приняло решение повести страну по пути к абсолютно свободному рынку. Государство устранилось от участия в экономике (прим. автора: регулированием экономики занялась группа молодых чилийских экономистов), его функции свелись к охране режима. По сути, стабильность в обществе поддерживалась авторитарными методами, она держалась только за счет жесткой военной диктатуры. В этом состоит ключевая особенность решений власти, выбравшей путь «шоковой терапии». - Чтобы провести страну через весь алфавит «шоковой терапии», нужна сильная авторитарная власть.

Сам ход чилийских реформ, получивших название «шоковая терапия», был последовательно реализован. На первом этапе было принято решение о проведении сокращения денежной массы. В результате «инфляция, составлявшая в 1975 году 341\%, упала, а 20\% предприятий разорилось, безработица выросла за два года с 9,1\% до 18,7\%. Производство упало на $13 \%{ }^{17}$. После этого была проведена

\footnotetext{
${ }^{17}$ Буйвинд Э. Прощай, "чилийское чудо" http://rus.delfi. Iv/archive/article.php?id=16512630
} 


\section{Тренды и управление - № 2 (2)•2013}

приватизация государственных предприятий. «Из 507 государственных предприятий было приватизировано 480 - 95\%, ограничений не было - все покупали, что хотели и сколько хотели на банковские кредиты» ${ }^{18}$.

В результате этих изменений «экономика под давлением свободы рухнула. Производство сократилось на 28\%, безработица выросла до 34,6\%. Оценивая показатель ВНП с 1972 года по 1987 год в расчете на душу населения, можно сказать, что вместо ежегодного прироста этого показателя, он упал на $6,4 \%$. В 1989 году 41,2\% населения жили ниже черты бедности, а треть из них - умирали с голоду и поддерживались только бесплатными суповыми кухнями международных организаций помощи. Средняя зарплата сократилась на $55 \%$, работу в Чили имели всего $38 \%$ населения. Страна залезла в долги, на обслуживание долга в 1985 году уходило 48,4\% выручки от экспорта» ${ }^{19}$.

Картину в Чили можно дописать сведениями о том, что граждане этой страны подверглись репрессиям, данные о жертвах по-прежнему разнятся, но их факт сегодня никто уже не отрицает. Оппозиция в Чили была подавлена, ее лидеры подверглись преследованию. Также в этот период отмечена массовая эмиграция чилийцев из страны ${ }^{20}$.

В 1990 году 74-летний Пиночет, уверовав в экономическое чудо, решился пойти на выборы и проиграл их, одно сохранил за собой пост главнокомандующего сухопутными войсками и влияние в политической жизни страны. Лишь только в 1998 году он окончательно ушел в отставку, сохранив за собой пост пожизненного сенатора. С 1998 по 2006 годы Пиночету были

${ }^{18}$ Буйвинд Э. Прощай, "чилийское чудо" http://rus.delfi. Iv/archive/article.php?id=16512630

${ }^{19}$ Буйвинд Э. Прощай, "чилийское чудо" http://rus.delfi. Iv/archive/article.php?id=16512630

${ }^{20}$ Панкратов С.А. Модернизация России: поиск модели устойчивого развития. В., 2006 С. 109 предъявлены различные обвинения в похищении людей, пытках, наркоторговле, уходе от налогов, убийстве 21. В декабре 2006 года Пиночет умирает. «После смерти бывшего диктатора чилийское общество оказалось в известном смысле расколотым: 11 декабря 2006 года в Сантьяго было ознаменовано многолюдными ликующими выступлениями противников Пиночета с одной стороны и не менее многолюдными траурными собраниями сторонников покойного - с другой» ${ }^{22}$.

Такой дуализм отношения к Пиночету и его реформам в обществе в научных кругах не позволяет однозначно оценить его решения в период модернизации. Тем не менее, можно констатировать, что бескомпромиссное авторитарное внедрение принципиально новой экономической модели - это всегда шок для общества. Опыт Чили свидетельствует нам о том, что такое возможно только в условиях авторитарной модели. Пиночет как военный руководитель Чили справился с этой задачей, типичными военными мерами он обеспечил безопасный ход реформ. При проведении реформ руководство Чили не задумывались об их социальной стоимости.

Сегодня «сторонники Чикагской школы не отрицают социальных издержек «чилийского чуда», утверждая, что эффект реформ последовал лишь после ухода А.Пиночета. По их логике либерализация цен, иностранный долг Чили, растущий год от года, отказ от социальных программ и поддержки инфраструктуры должны были привести к тому, что экономика Чили отформатируется в соответствии с возможностями ресурсной базы и «гражданского общества» Чили. Правда, до сих пор, судя по

\footnotetext{
${ }^{21}$ См. Пиночет, Аугусто http://ru.wikipedia.org/wiki/ Пиночет

${ }^{22}$ См. Пиночет, Аугусто http://ru.wikipedia.org/wiki/ Пиночет
} 
уровню бедности в Чили (18\% населения), реформы никак не принесут своих плодов» ${ }^{23}$.

Решения чилийского руководства периода «чилийского чуда» были проведены в интересах обогащения определенных бизнесструктур (из круга избранных), в этой части, реформы оказались эффективными (прим. автора: то есть если ставились такие иеели, то иели были достигнуты). Если же говорить о социальной ориентированности реформ, то с этой позиции чилийские реформы выглядят не эффективными, а скорее провальными.

Таким образом, анализ трех моделей принятия решений показал, что в условиях модернизации для проведения ориентированных на общество реформ, правящей элите необходимо сконцентрировать в своих руках всю полноту власти, все ресурсы. Опыт Германии и опыт США показывают нам, что только при концентрации ресурсов в руках правящей элиты и полного понимания целей реформ возможен быстрый и качественный скачек общества успешная модернизация.

Различия между тоталитарными и демократическими моделями принятия решений заключается лишь в целесообразности их применения на определенном витке истории. Также применение этих моделей может зависеть от территориальных, национальных и исторических особенностей обществ, в которых эти модели используются. История показывает, что тоталитарные модели позволяют осуществить модернизацию в короткие исторические промежутки (в течение 3-5 лет), модернизация становится целью всего общества. В демократических моделях этот временной промежуток может быть растянут на десятилетия, кроме того, сам модернизационный процесс может захлебнуться в демократическом плюрализме. Модернизацию, как нам кажется, сложнее всего проводить именно в рамках демократической

${ }^{23}$ В России снова вспомнили про чилийское финансовое чудо http://top.rbc.ru/economics/03/07/2008/194783.shtml модели. Однако, если модернизацию в рамках демократической модели удается реализовать, то лидеры страны, ответственные за модернизацию получают колоссальный уровень доверия в обществе. Соответственно, через этот уровень доверия укрепляются властные позиции этих лидеров, пример, американского президента Франклина Делано Рузвельта наглядное тому подтверждение.

Авторитарные модели, с нашей точки зрения, не годятся для модернизации. Они сеют хаос в обществе, провоцируя противостояние на уровне «диктатор - борцы с режимом». От модернизации авторитарной модели выигрывает только правящая элита, спекулирующая на общественном достоянии (прим. автора: сырьевая база государства), такие режимы не имеют исторической перспективы. Как правило, авторитарные режимы сбрасываются революционной волной после того, как пузырь общественного терпения лопается. Модернизация в авторитарных режимах может растягиваться на десятилетия и быть настоящим бичом общества. В этой связи, модернизация в условиях авторитарной модели принятия решений представляется нам проектом весьма туманным и малоперспективным.

Несомненно, для того, чтобы точно оценить, какая из моделей принятия решений наиболее эффективна в условиях модернизации, важно оценить сам «исторический момент модернизации». Однако, нам кажется, что ключевым фактором в выборе конкретной модели является количество основных инициаторов модернизации, готовых брать на себя всю полноту ответственности за преобразования. Количество инициаторов может варьироваться от нуля и единицы до какого-то множества.

То есть если ответственность за модернизацию брать не хочет никто, но модернизацию, вроде как надо проводить, то лидеры (прим. автора: ответственные за принятие решений, элита, стоящая у власти) могут широко при- 


\section{Тренды и управление - № 2 (2)•2013}

менять авторитарную модель, сваливая неудачи на коррупцию, дефицит бюджета и прочее. В этом случае все модели принятия решений можно ранжировать следующим образом: авторитарная, тоталитарная, демократическая.

Если ранжировать модели принятия решений по уровню их эффективности в условиях модернизации, то самыми эффективными моделями модернизации, с оговоркой, что государство является единственным инициатором модернизации, по убывающей будут: тоталитарная модель, затем демократическая, завершает этот условный рейтинг авторитарная модель.

Если инициаторов модернизации некое множество, и они готовы справедливо разделить ответственность за результат, то, несомненно, этот условный рейтинг возглавит со значительным отрывом демократическая модель, далее пойдут тоталитарная и авторитарная модели.

Как мы видим, проблема выбора эффективной модели принятия решений в условиях модернизации зависит от целей правящих элит и их желания брать на себя ответственность за достижение этих целей, опыт зарубежных стран наглядное тому подтверждение.

И в заключение хочется вернуться к российской модернизации, начало которой в 2009 году было обозначено в манифесте Президента РФ «Россия, Вперед!» ${ }^{24}$ Сегодня в стране уже сформировалась определенная модель принятия решений, насколько она эффективна - покажет история. Цели российской модернизации заявлены и активно подхвачены правящей партией, ответственной за ход ее реализации. Очень хочется надеяться, что модернизация в России окажется успешной. Хочется верить,

${ }^{24}$ Медведев Д.А. Россия, вперёд! http://www.kremlin. ru/news/5413 что здоровые силы в руководстве страны, ответственные за этот процесс, учли российский исторический опыт и опыт зарубежных стран в проведении сложных преобразований, имеют четкий план проведения реформ, действуют в соответствии с этим планом, избегая экспромта.

\section{Библиография:}

1. Атаманчук Г. В. Теория государственного управления. М.: 1997

2. Буйвинд Э. Прощай, «чилийское чудо» http:// rus.delfi.lv/archive/article.php?id=16512630

3. В России снова вспомнили про чилийское финансовое чудо http://top.rbc.ru/ economics/03/07/2008/194783.shtml

4. Кангас С. Чикагские мальчики и чилийское экономическое чудо http://www.scepsis.ru/ library/id_557.html

5. Медведев Д.А. Россия, вперёд! http:// kremlin.ru/news/5413

6. Минаев С. Чилийское экономическое чудище http:/www.kommersant.ru/doc. aspx?DocsID $=731005$

7. Миронин C.С. Антидепрессивная политика Обамы, Сталина, Гитлера и Рузвельта http://www.zlev.ru/index.php?p=article\&no mer $=12$ \&article $=562$

8. Могилевский В.Д. Методология систем. М.: Экономика, 1999

9. Новый курс Рузвельта, см. например http:// ru.wikipedia.org/wiki/Новый_курс

10. Панкратов С.А. Модернизация России: поиск модели устойчивого развития. В., 2006

11. Пиночет, Аугусто, см. например http:// ru.wikipedia.org/wiki/Пиночет

12. Системный анализ и принятие решений: Словарь-справочник: Учебное пособие для вузов / Под ред. В.Н. Волковой, В.Н. Козлова. - М.: Высш. шк., 2004.

13. Соколов А.В. Политический риск от теории к практике. М.: Поколение. , 2009 
14. Экономика Третьего рейха до и во время войны, см. например http://ru.wikipedia.org/ wiki/Третий рейх

15. Эффективность государственной власти и управления в современной России. под ред. Игнатова В., Р-на-Дону: 1998

\section{References (transliteration):}

1. Atamanchuk G. V. Teoriya gosudarstvennogo upravleniya. M.: 1997

2. Buyvind E. Proschay, «chiliyskoe chudo» http:// rus.delfi.lv/archive/article.php?id=16512630

3. V Rossii snova vspomnili pro chiliyskoe finansovoe chudo http://top.rbc.ru/ economics/03/07/2008/194783.shtml

4. Kangas S. Chikagskie mal'chiki i chiliyskoe ekonomicheskoe chudo http://www.scepsis.ru/ library/id_557.html

5. Medvedev D.A. Rossiya, vpered! http:// kremlin.ru/news/5413

6. Minaev S. Chiliyskoe ekonomicheskoe chudische http://www.kommersant.ru/doc. aspx?DocsID $=731005$
7. Mironin S.S. Antidepressivnaya politika Obamy, Stalina, Gitlera i Ruzvel'ta http:// www.zlev.ru/index.php? $p=$ article $\&$ nomer $=1$ $2 \&$ article $=562$

8. Mogilevskiy V.D. Metodologiya sistem. - M.: Ekonomika, 1999

9. Novyy kurs Ruzvel'ta, sm. naprimer http:// ru.wikipedia.org/wiki/Novyy_kurs

10. Pankratov S.A. Modernizaciya Rossii: poisk modeli ustoychivogo razvitiya. V., 2006

11. Pinochet, Augusto, sm. naprimer http:// ru.wikipedia.org/wiki/Pinochet

12. Sistemnyy analiz i prinyatie resheniy: Slovar'spravochnik: Uchebnoe posobie dlya vuzov / Pod red. V.N. Volkovoy, V.N. Kozlova. - M.: Vyssh. shk., 2004.

13. Sokolov A.V. Politicheskiy risk ot teorii $\mathrm{k}$ praktike. M.: Pokolenie. , 2009

14. Ekonomika Tret'ego reyha do i vo vremya voyny, sm. naprimer http://ru.wikipedia.org/ wiki/Tretiy_reyh

15. Effektivnost' gosudarstvennoy vlasti i upravleniya v sovremennoy Rossii. pod red. Ignatova V., R-na-Donu: 1998 